\title{
FINANCIAL VIABILITY OF DISTRICT MUTUAL HEALTH INSURANCE SCHEMES OF LAWRA AND SISSALA EAST DISTRICTS, UPPER WEST REGION, GHANA
}

\author{
S. K YEVUTSEY ${ }^{1}$ and M. AIKINS ${ }^{2}$ \\ ${ }^{1}$ Ministry of Health, Head Office, P. O. Box M44, Accra, Ghana. ${ }^{2}$ School of Public Health, College of Health \\ Sciences, University of Ghana, P. O. Box LG13, Legon, Ghana.
}

Correspondence Author: Dr Moses Aikins

E-mail: maikins57@yahoo.com

Conflict of Interest: None declared

\section{SUMMARY}

Introduction: The National Health Insurance Act, passed in 2003 mandates the National Health Insurance Authority to, in conjunction with the district assemblies establish district mutual health insurance scheme (DMHIS) governed by semi-autonomous boards in all ten regions. Since its implementation, unsubstantiated reports indicate increasing health care and administrative costs of the various DMHIS across the country without any corresponding increase in the premium level. We sought to assess the financial viability of the DMHIS in Lawra (LDMHIS) and Sissala East (SEDMHIS) districts, Upper West Region of Ghana.

Methods: Cost analysis of revenue and expenditure of LDMHIS and SEDMHIS from 2004 to 2007 was used to estimate the revenue, expenditure, administrative cost, expense, claims and combined ratios.

Results: The scheme's major sources of revenue were funds from NHIA on behalf of exempted group and the formal sector employees and premium collected from the informal sector. Other sources of revenue were significant at the beginning and became almost negligible at the end of 2007. At the end of 2005, administrative cost was higher than medical claims. By the end of 2007 , it has reduced to $34.3 \%$ and $15.7 \%$ of the total expenditure of the SEDMHIS and LDMHIS respectively. The combined ratios decreased from 2.27 and 1.17 in 2005 to 0.74 and 0.95 in 2007 for SEDMHIS and LDMHIS respectively.

Conclusion: Continuous NHIA support, increasing coverage of the scheme and a corresponding reduction in administrative cost would increase revenue. If this is sustained, the schemes could be financially viable in the long term.

Key words: District Mutual Health Insurance Scheme, claims ratio, expense ratio, combine ratio, administrative costs, Ghana

\section{INTRODUCTION}

At Ghana's independence in 1957, user charges in government health facilities were abolished and thus health services were provided free of medical charges in all public health institutions throughout the country. However, as the country's population started growing coupled with worsening economic conditions, much pressure was placed on the limited resources forcing the Government to seek alternative ways of financing the health sector.

This resulted in the introduction of user fee through a cost-sharing mechanism at all public health facilities in 1969 with the enactment of the Hospital Fee Decree ${ }^{1}$, which was later amended to the Hospital Fees Act. ${ }^{2}$ In 1985, the government again published Hospital Fee Regulation $^{3}$ to re-emphasize the Hospital Fee Act.

The removal of subsidies and the intensification of fee collection for health services under the Hospitals Fee Act were among the components of the Government's Economic Policy in the mid 1980 and 1990 (i.e. Economic Recovery Programme (ERP)). Realising the potentially adverse impact of this economic programme at the household and community levels, and on the very success of the ERP itself, the government initiated the Programme of Actions to Mitigate the Social Costs of Adjustment (PAMSCAD).

The health component of PAMSCAD involved the provision of essential drugs within the primary health care (PHC) framework. In 1988, modifications were made to the Hospital Fee Act that included the supply of drugs at full cost to patients. Provisions were also made for health facilities to retain increasing proportions of their revenue. The Ministry of Health (MOH) then adopted a list of essential drugs for use within the public sector. Problems of procurement of drugs and the inequitable allocation of drugs to health facilities prompted the introduction and implementation in 1992 of the "Cash and Carry" scheme, formally known as the Revolving Drug Fund.

Concurrently, the government defined entitlements to full or partial exemption from paying hospital fees under Legislative Instrument (LI 1313) that set up the 
Hospital Fees Regulation of $1985 .^{3}$ Some services were also made free of charge, including immunisation, antenatal and post-natal services and treatment at child welfare clinics. ${ }^{4}$

The user fees were heavily criticised for their negative impact on equity and access. They were found to have led to financial access problems or even exclusion of the poor from healthcare utilization. ${ }^{5}$ High user fee charges caused a drop in utilization rates and eventually delays in seeking care.

The implementation of the "cash and carry" scheme compounded the utilization problem by creating some financial barrier to health care access. ${ }^{6,7}$ The scheme which was the health care financing option before 2001 was claimed to have created problem in accessing healthcare. ${ }^{8}$ On the contrary, the scheme was claimed to have increased revenue base for care providers. ${ }^{9}$

Several proposals for running a national health insurance scheme had been under consideration in the country since the early 1980s from numerous groups including the International Labour Organization, World Health Organization, European Union and London School of Hygiene and Tropical Medicine.

A private consultancy group which also conducted a feasibility study into the establishment of a National Health Insurance Scheme in Ghana, recommended the adoption of a centralized NHIS for the formal sector and a pilot "rural-based community-financed schemes" for the non-formal sector. Various schemes were piloted and notable amongst them were the Nkoranza Community Health Insurance Scheme (1992) and the West Gonja Health Insurance Scheme (1995).

In the mid 1990s, the MOH created a unit to establish national health insurance as an alternative to 'cash and carry ${ }^{, 10}$. Despite unsuccessful pilot projects in the Eastern region, the Social Security and National Health Insurance Trust (SSNIT) started planning for another centralized health insurance scheme to be run by a company called the Ghana Health Care Company. ${ }^{10}$ This project also did not come to fruition.

In August 2003, the Government of Ghana passed a National Health Insurance Act ${ }^{11}$ that aimed to improve access and quality of basic health care services in Ghana through and among other to establish of mandatory district level mutual health organizations. The Legislative Instrument ${ }^{12}$ to establish the operational framework for the National Health Insurance Scheme (NHIS) was also passed in December 2004 to further guide the implementation efforts. The NHIS is run nationally by the National Health Insurance Authority
(NHIA) an autonomus body set up to facilitate, coordinate and regulate the health insurance schemes. ${ }^{13}$

The NHIA has established regional offices in all the ten regions of the country and these offices collaborate with the Regional Health Directorates of the Ghana Health Service for proper functioning of the Schemes. Monitoring and Evaluations of District Mutual Health Insurance Schemes (DMHISs) are also carried out in the region by the Health Insurance Regional Offices.

At the district level the NHIA in conjuction with the district assemblies has established the DMHIS which is governed by a semi-autonomous Board of Directors. The DMHIS mobilises revenue from the informal sector and receives claims from accredited providers for vetting before reimbursements.

The financial viability of the NHIS depends on the ability of the schemes to generate revenue that would meet its financial obligations. The premium collected from the informal sector and the financial support from the NHIA are the main sources of revenue for the DMHISs. The financial obligation of the DMHISs includes the expenditure on health care claims as well as administrative costs.

Financial viability in this study refers to the Scheme's ability to generate sufficient revenue to meet its expenditure and, to allow growth while maintaining service levels. Thus, financial viability of DMHIS is a balance between its income (revenue) and expenditure. ${ }^{14}$ Revenue accrues from high participation rate by the target population and this provides a crude indicator of the scheme's acceptance. ${ }^{15}$

Health care claims from providers are major source of expenditure for the scheme. This is made up of cost of drugs and cost of non-drug related services. The financial performance of the DMHISs is a function of the premium collected, the cost of health care services of the insured, the level of external subsidy, the size of the pool, and degree of economies of scale that is achieved. $^{16}$

Financial access to health services in Ghana will facilitate the achievement of the Milleniun Developement Goals. There are media reports of increasing health care costs and operational costs of the various District Mutual Health Insurance Schemes (DMHIS) across the country. The level of premium from the informal sector remains at almost the same level as it was from the start of the schemes and these events threaten the financial viability of the schemes. 
The 2006 Annual Report of the Upper West Region of Ghana indicated an increase in both out-patient department (OPD) visits and in-patient care charges for the insured especially in the Sissala East District. The annual report also suggested that there were wide variations in the service charges for the insured in the entire region. According to the Report, Sissala East District recorded the highest average cost of treatment for the insured while Lawra District had the lowest. ${ }^{17}$

The implementation of NHIS in the region aims to remove the financial barrier and enhance access to health care services especially for the poor. The Upper West Region is one of the poorest regions in Ghana and has establised health insurance schemes in all its districts. The assessment of the revenue and expenditure of the region's DMHISs since their implementation is thus crucial to ascertaining the financial viability of the Schemes. Furthermore, it will provide an indication of improvement in financial access for the poor in the region. This paper assesses the revenue and expenditure of the selected DMHISs in the Upper West Region of Ghana.

\section{Conceptual framework}

The conceptual framework for this study shows that the magnitude of revenues and expenditures for the DMHIS will determine the balance between viability and non-viabilty of the scheme. Like a balance scale, the revenue arm should be more than the expenditure arm, for the scale to tilt towards viability. The measure of revenue effect will be determined by the revenue status, whilst the expenditure effect will be determined by the expense, claims and the combined ratios. These ratios will determine the financial status of any district mutual health insurance scheme. The combined ratio is the summation of the expense ratio and the claims ratio. The combined ratio provides indirect indication of the financial status of the Scheme. A combine ratio of less than one indicates the Scheme has broken even.

\section{METHODS}

\section{Study sites}

The two DMHISs are located in Sissala East and Lawra districts of the Upper West Region of Ghana. The estimated populations of Lawra and Sissala East districts in 2007 were 98,487 and 50,916 respectively. It is estimated that only about $15 \%$ of the adult population of the region are literate ${ }^{17}$. Lawra District has eight health sub-districts with two hospitals located at Nandom and Lawra; eight Community Health Planning Services (CHPS) compounds and one accredited private clinic.

The Sissala East District has five health sub-districts with one hospital at Tumu; two CHPS compounds and no accredited private health facilities. The Sissala East
DMHIS started enrolment of the insured in October 2004 but commenced business on $1^{\text {st }}$ April 2005, whilst the Lawra DMHIS started as Community Mutual Health Insurance Scheme on the $1^{\text {st }}$ June 2004, but was converted to a DMHIS in October 2005.

\section{Data collection techniques}

Structured revenue and expenditure data collection forms were used for data collection. The data on the annual premium from the informal sector was obtained from the DMHIS registers, the accounts ledger books and the monthly reports submitted to the NHIA. Information on the financial support from the NHIA which comes as National Health Insurance Fund (NHIF) subsidy and administrative support were also obtained from the accounts ledgers books of the Schemes.

The NHIF subsidy is a contribution from NHIA as premium payment on behalf of the formal sector employees or SSNIT contributors and the exempt groups (children under 18 years, the aged, pensioners and the indigents). Other sources of revenues such as interest on investment, donations etc. were also obtained from the accounts ledgers.

Data on annual health care claims and administrative cost were obtained from accounting ledgers, payment vouchers and receipts of payment for the DMHISs in the two districts. Expenditure data on health care claims submitted by providers was usually divided into two main line items, namely drugs and services bills. These data were obtained from the Claims Management Unit and accounting ledger books.

The expenditure data on operations of the Schemes were captured on the following main line items in the ledger book: transport/fuel, meetings, utilities, office consumables, salaries and wages, commission and sensitization training workshops. The other expenditure items that did not fall directly under any of the main line items were placed in the 'Other category'.

\section{Data analysis}

All the revenue and expenditure data of the Sissala East and Lawra District Mutual Health Insurance Scheme (DMHIS) covered the period 2004 and 2007. Revenue data comprised records on total monthly informal sector premium, financial support from NHIA that comes as administrative support and government premium payment for the exempt groups. Data on expenditure is made up of medical claims from the health facilities (i.e. drugs and services costs) and administrative cost.

\section{Revenue estimations}

Estimation of Total Informal Sector Premium: The annual total premium from the informal sector was de- 
termined by adding all premiums paid by the registrants/insured in a year over the 2004 to 2007 period.

Estimation of Annual Financial Support from the NHIA: The annual total support from the NHIA was estimated by adding all monies received from the NHIA specifically meant for the exempt categories. Administrative support from the NHIA was also added separately on annual basis.

Estimation of Other Sources of revenue: The total of Other Source of revenue was estimated by adding donations from NGOs, financial support from District Assemblies, etc between 2004 and 2007.

\section{Expenditure estimations}

Estimation of Annual Health Care Claims: The annual health care claims submitted by providers to the Schemes were calculated by adding all submitted drugs and services bills from the Scheme's accredited health care providers in the districts over the period of 2004 to 2007.

Estimation of Annual Administrative Cost: The annual administrative/operational cost was calculated by adding all cost accruing from transport/fuel, salaries/wages, meetings, utility bills, office consumables, commission on the collected premium from the informal sector and other office administrative costs.

Estimation of proportion Administrative Cost: This was calculated by dividing the total administrative expenditure with the total expenditure of the Schemes.

\section{Performance indicators estimations}

Expense Ratio: This was estimated by dividing administrative (operational) cost by total annual premium collected from the informal sector.
Claims Ratio: This was estimated by dividing health (medical) claims with the total premium collected from the informal sector in the districts.

Combined ratio: This ratio is the summation of the expense ratio and the claims ratio.

All the cost analysis and graphs were carried out using 2003 Microsoft Excel Software programme.

\section{Ethical Issues}

The proposal for the study was approved by the Ghana Health Service Ethical Review Committee. Permission was also sought from the Regional Directorate of Health Services, District Chief Executives, the Schemes Management and the District Director of Health Services (DDHS) prior to data collection. The Scheme's Managers were also assured of the confidentiality of their data, data safety and usage purposely for academic work. There were no known risks of using the data, and benefits of using the collected data were immense to provide important information on the schemes.

\section{RESULTS}

\section{Health Insurance Coverage}

The insurance coverage of the two populations have increased since the implementation of the district health insurance scheme. Table 1 shows that as at the end of 2007, registration coverage of Sissala East District has increased from $15.4 \%$ in 2005 to $73.2 \%$, whilst that of the Lawra district has increased from $8.3 \%$ in 2005 to $40.5 \%$.

Table 1 District Mutual Health Insurance Scheme Coverage of Sissala East and Lawra Districts

\begin{tabular}{|l|l|l|l|l|l|l|l|l|}
\hline \multicolumn{2}{|c|}{ Sissala East District Mutual Health Insurance Scheme } \\
\hline \multirow{2}{*}{ Year } & \multirow{2}{*}{$\begin{array}{l}\text { District } \\
\text { population }\end{array}$} & $<18 \mathrm{yrs}$ & $>70 \mathrm{yrs}$ & $\begin{array}{l}\text { Formal } \\
\text { sector }\end{array}$ & $\begin{array}{l}\text { Informal } \\
\text { sector }\end{array}$ & Pensioners & Indigents & $\begin{array}{l}\text { Total } \\
\text { erage (\%) }\end{array}$ \\
\cline { 2 - 10 } cov- \\
\hline 2005 & 55,216 & 2,430 & 3,548 & 914 & 1,275 & 80 & 270 & 15.4 \\
\hline 2006 & 50,065 & 7,474 & 3,804 & 1,324 & 3,700 & 98 & 250 & 33.3 \\
\hline 2007 & 50,916 & 19,835 & 4,694 & 1,385 & 10,951 & 127 & 258 & 73.2 \\
\hline Lawra District Mutual Health Insurance Scheme & \\
\hline 2005 & 95,222 & 2,713 & 2,102 & 1,198 & 1,567 & 151 & 125 & 8.3 \\
\hline 2006 & 96,841 & 10,204 & 2,901 & 1,864 & 6,821 & 126 & 390 & 23.0 \\
\hline 2007 & 98,487 & 22,774 & 4,183 & 1,064 & 11,012 & 78 & 730 & 40.5 \\
\hline
\end{tabular}

\section{Estimated Revenue of the Schemes}

The main sources of revenue for the two schemes were payments of premium by the informal sector and financial support from NHIA as shown in Table 2. There was a general increase in the revenue from the NHIA to the two schemes. The financial support from NHIA constitutes the highest source of revenue to the schemes. For Sissala East District Mutual Health In- 
surance Scheme (SEDMHIS), the percentage of NHIA support to the scheme ranges between $63.1 \%$ in 2005 and $85 \%$ in 2007, whilst LDMHIS received between $48.9 \%$ in 2004 and $81.6 \%$ in 2007 of its total revenue from the NHIA. The total informal sector premium shows a general decrease in percentages of the total revenue received by the two Schemes. Other sources of revenue to the two Schemes such as NGOs donations, financial support from the District Assemblies and interest on investment dropped drastically.

\section{Estimated Expenditure of the Schemes}

Table 3 shows the proportion of medical claims cost and administrative cost to the total expenditure of SEDMHIS and LDMHIS from 2005 to 2007. At the beginning of each Scheme, medical claims formed a small part of the expenditure. It also depicts a systematic rise in the medical claims cost as a proportion of the total expenditure from $4.5 \%$ in 2005 to $65.7 \%$ in 2007 for SEDMHIS. The administrative cost also dropped from $95.5 \%$ in 2005 to $34.3 \%$ in 2007 . A similar trend was found in LDMHIS with a gradual decrease in the proportion of administrative cost of the total expenditure from $91.3 \%$ in 2005 to $15.7 \%$ in 2007 with a corresponding increase in medical claim cost from $8.7 \%$ in 2005 to $84.3 \%$ in 2007 .

Table 2 Estimated Annual Revenue of the District Mutual Health Insurance Scheme

\begin{tabular}{|c|c|c|c|c|c|c|c|c|}
\hline & \multicolumn{4}{|c|}{ Revenue from SEDMHIS } & \multicolumn{4}{|c|}{ Revenue from LDMHIS } \\
\hline Year & $\begin{array}{l}\text { Informal } \\
\text { Sector } \\
\text { Premium } \\
(\%)\end{array}$ & $\begin{array}{c}\text { NHIA } \\
\text { subsidy } \\
(\%)\end{array}$ & $\begin{array}{c}\text { Others } \\
(\%)\end{array}$ & $\begin{array}{l}\text { Total reve- } \\
\text { nue }(\mathrm{GH} \phi)\end{array}$ & $\begin{array}{c}\text { Informal } \\
\text { Sector } \\
\text { Premium } \\
(\%) \\
\end{array}$ & $\begin{array}{c}\text { NHIA } \\
\text { subsidy } \\
(\%)\end{array}$ & $\begin{array}{c}\text { Others } \\
(\%)\end{array}$ & $\begin{array}{c}\text { Total } \\
\text { revenue } \\
(\mathrm{GH} \phi)\end{array}$ \\
\hline 2004 & N/A & NA & N/A & N/A & 11.4 & 48.9 & 39.7 & $30,701.74$ \\
\hline 2005 & 17.3 & 63.1 & 19.6 & $38,410.20$ & 28.8 & 33.7 & 37.5 & $38,961.20$ \\
\hline 2006 & 19.9 & 73.3 & 6.8 & $128,549.60$ & 34.7 & 49.3 & 16.0 & $141,449.25$ \\
\hline 2007 & 14.3 & 85.0 & 0.6 & $433,674.40$ & 13.8 & 81.6 & 4.6 & $620,964.29$ \\
\hline
\end{tabular}

Table 3 Proportions of Medical Claims and Administrative costs of the Total Expenditure

\begin{tabular}{|l|c|c|c|c|c|c|}
\hline & \multicolumn{3}{|c|}{ Expenditure of SEDMHIS } & \multicolumn{3}{c|}{ Expenditure of LDMHIS } \\
\hline Year & $\begin{array}{c}\text { Medical } \\
\text { Claims Cost } \\
(\%)\end{array}$ & $\begin{array}{c}\text { Administrative } \\
\text { Cost }(\%)\end{array}$ & $\begin{array}{c}\text { Total Expendi- } \\
\text { ture }(\mathrm{GH} \phi)\end{array}$ & $\begin{array}{c}\text { Medical } \\
\text { Claims Cost } \\
(\%)\end{array}$ & $\begin{array}{c}\text { Administrative } \\
\text { Cost }(\%)\end{array}$ & $\begin{array}{c}\text { Total Expendi- } \\
\text { ture }(\mathrm{GH} \phi)\end{array}$ \\
\hline 2005 & 4.5 & 95.5 & $57,388.75$ & 8.7 & 91.3 & $28,378.48$ \\
\hline 2006 & 48.0 & 52.0 & $105,455.70$ & 79.5 & 20.5 & $222,822.96$ \\
\hline 2007 & 65.7 & 34.3 & $304,399.14$ & 84.3 & 15.7 & $563,875.35$ \\
\hline
\end{tabular}

\section{Comparison of Revenue and Expenditure}

Figure 1 shows the trend of the total revenue and total expenditure of the Schemes. In SEDMHIS, both revenue and expenditure increased in real terms over the period. However, in 2005, the total expenditure was higher than total revenue collected. There was a general increase in both revenue generated and the expenditure of LDMHIS. However, in 2006, the expenditure was higher than revenue generated.

\section{Expense, Claims and Combined Ratios}

Table 4 shows the trend of expense, claims and combined ratios of the two schemes. For SEDMHIS the expense ratio decreased from 2.17 in 2005 to 0.25 in 2007 while claim ratio appreciated from 0.1 in 2005 to 0.48 in 2007 . The combined ratio decreased from 2.27 in 2005 to 0.74 in 2007 . There was also a decline in the expense ratio from 1.06 in 2005 to 0.15 in 2007 for LDMHIS.

The claims ratio appreciated from 0.1 in 2005, increased to 1.49 in 2006 and declined to 0.8 in 2007. The combined ratios were also estimated as 1.17 in 2005, 1.88 in 2006 and 0.95 in 2007. 


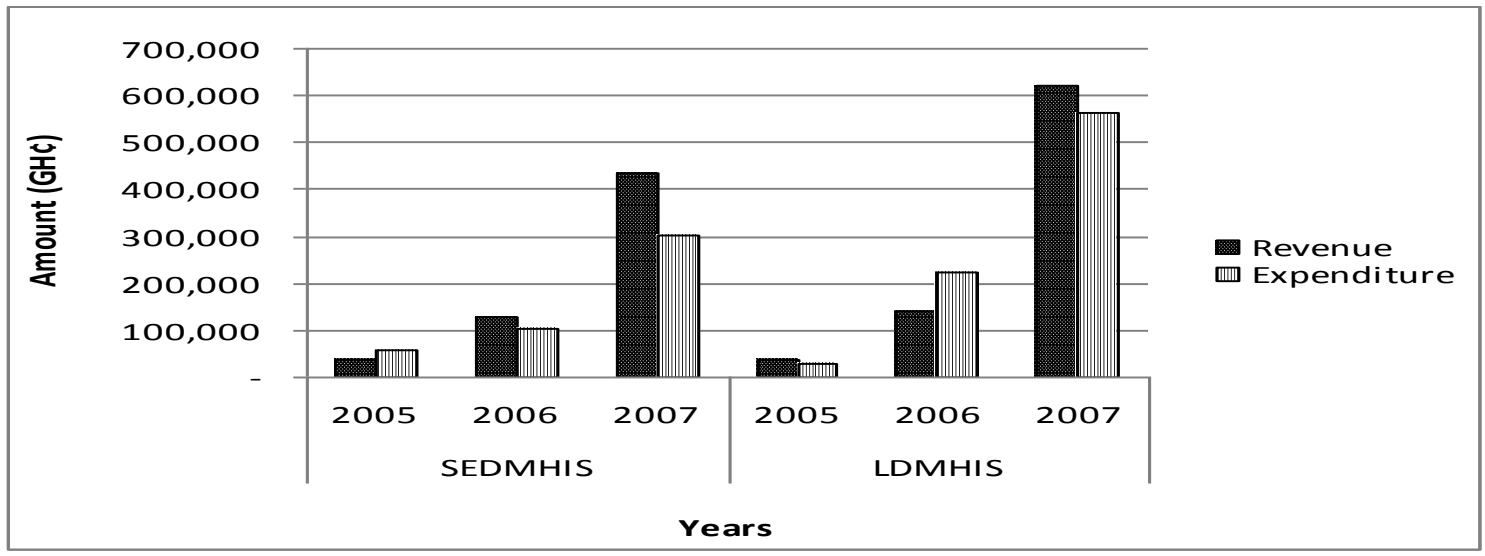

Figure 1 Trend of Total Revenue and Expenditure of the Schemes

Table 4 Expense, claims and combined ratios

\begin{tabular}{|c|c|c|c|c|c|c|}
\hline & \multicolumn{3}{|c|}{ SEDMHIS } & \multicolumn{3}{c|}{ LDMHIS } \\
\cline { 2 - 7 } Year & Expense Ratio & $\begin{array}{c}\text { Claims Ra- } \\
\text { tio }\end{array}$ & Combined Ratio & $\begin{array}{c}\text { Expense Ra- } \\
\text { tio }\end{array}$ & $\begin{array}{c}\text { Claims } \\
\text { Ratio }\end{array}$ & $\begin{array}{c}\text { Combined Ra- } \\
\text { tio }\end{array}$ \\
\hline 2005 & 2.17 & 0.10 & 2.27 & 1.06 & 0.10 & 1.17 \\
\hline 2006 & 0.47 & 0.43 & 0.90 & 0.39 & 1.49 & 1.88 \\
\hline 2007 & 0.25 & 0.48 & 0.74 & 0.15 & 0.80 & 0.95 \\
\hline
\end{tabular}

\section{DISCUSSION}

The paper has shown that the major sources of revenue of the Schemes were financial support from the NHIA and the informal sector premium contributions. The financial support from the NHIA is made up of subsidy and administrative support. Both Schemes experienced higher increases in NHIA subsidy over the three year period with LDMHIS receiving more revenue compared to SEDMHIS. This is as a result of higher coverage of exempted group in the Lawra District than Sissala East District in 2007.

One major limitation of the study was that at the time of data collection, the Schemes had no audited accounts. Therefore all the revenue and expenditure data were obtained from records and account ledger books. Secondly, due to improper record keeping and documentation of expenditures, some of the Lawra District Mutual Health Insurance Scheme (LDMHIS) expenditure data were incomplete. This has implication in the comparison of revenue to expenditure from the beginning of the Scheme in 2004.

The results show that the revenue from the NHIA is determined by the number of registered exempted group and the formal sector employees. Thus, for the Scheme to increase its revenue there is the need to register more people from their communities and also increase coverage by the informal sector.
This should serve as the driving force behind revenue mobilization drives of the two Schemes. The amount of administrative funds to the Schemes as a source of revenue was low compared to NHIA funds during the period.

Other relatively minor sources of revenue for the Schemes were from NGOs in the form of donations, financial support from the District Assemblies and interest on investment etc. For instance, SEDMHIS had about $20 \%$ of its total revenue mainly from DANIDA and District Assembly at the beginning of the Scheme in 2005 compared to $17 \%$ of the informal sector premium of the total revenue. Other sources of revenue continued to decline to about $6 \%$ in 2006 and $1 \%$ in 2007. This decline shows that Other sources of revenue are not sustainable and reliable as compared to the NHIA funds and the Informal sector premium. Similar situation pertained in LDMHIS, where the Other sources of revenue declined eventually to zero in 2007.

The total expenditure of the Schemes is made up of medical claims and administrative costs. The proportion of medical claims cost of the total expenditure of the two Schemes increased as administrative cost decreased. The increase in medical claims cost is as a result of increased coverage as well as members' high utilization of health care services. 
The higher proportion of administrative costs observed at the commencement of the Scheme was also due to high cost of establishing the Schemes. For instance more revenue collection points were erected in all the communities in order to increase coverage.

The proportion of medical claims cost and administrative cost of the total expenditure of LDMHIS was higher $(84 \%)$ compared to $66 \%$ of the SEDMHIS in 2007. This could be explained by the high number of accredited health facilities in the Lawra district thus increasing access to health care. Results from the estimated revenue and expenditure of the SEDMHIS for the period showed a mixed picture: the Scheme's revenue exceeded expenditure in both 2006 and 2007. Trends of revenue and expenditure of SEDMHIS shows that there was a deficit of $49 \%$ of revenue for the Scheme in 2005. There was less enrolment therefore low revenue generated. Another contributing factor was the high initial administrative cost of the Scheme. Other studies on social health insurance in OECD countries recorded lower administrative cost (i.e., 3.7-6.7\%). ${ }^{18}$ There are relatively mature schemes. This explains the excess expenditure over the revenue. As enrolment continued to increase, the revenue base also increased. A surplus of 29\% was made in 2006 and $30 \%$ in 2007 . Such annual surpluses, coupled with prudent cost containment and management will culminate into financial stability of the Scheme.

In the case of LDMHIS there were surpluses in 2005 and 2007. The year 2006 saw deficit of about $58 \%$ of the revenue generated. This could be attributed to relatively low enrolment and high administrative cost. The LDMHIS made another surplus in 2007 of about $9 \%$ of the total revenue.

The claims ratio of SEDMHIS increased from 0.1 in 2005 to 0.5 in 2007. This means that on average $\mathrm{GH} \phi 0.10$ and $\mathrm{GH} \phi 0.50$ of each $\mathrm{GH} \phi 1.00$ contribution collected were used for the payment of health care services of the insured in 2005 and 2007 respectively. Similarly, in the same period, LDMHIS also used $\mathrm{GH} \phi 0.10$ and $\mathrm{GH} \phi 0.80$ respectively of each $\mathrm{GH} \varnothing 1.00$ contribution collected. Studies of claim ratios of voluntary health insurers in the European Union also shows higher average ratio of about $0.79 .^{19}$

The expense ratio for SEDMHIS reduced from 2.17 in 2005 to 0.25 in 2007. This implies that more expenses were made from premium collected in 2005 as compared to 2007. It also indicates that $\mathrm{GH} \notin 2.17$ of each $\mathrm{GH} \phi 1.00$ contribution collected in 2005 , was spent on administrative issues. Conversely, in 2007, the Scheme used only $\mathrm{GH} \phi 0.25$ of the $\mathrm{GH} \phi 1.00$ contribution collected.
The combined ratio provides some indirect indication of the financial statuses of the Schemes. A combined ratio of less than one indicates that the scheme has broken even. As the results indicates that SEDMHIS showed improvement in its financial status with decrease in the combined ratios in 2006 and 2007. However, LDHMIS only showed combined ratio of less than one in 2007.

Most studies on NHIA in Ghana have principally focused on the evolution of the health insurance ${ }^{10}$, feasibility of rural health insurance schemes ${ }^{20}$, financial access to health care ${ }^{6,21}$, management of the schemes ${ }^{22}$ and social protection nature of the schemes. ${ }^{23}$ Little work has been done on the assessment of the performance of health insurance schemes in terms of their financial viability in Ghana.

The results of these two case studies indicate that for the Schemes to be financially viable, their revenues should always exceed their expenditures. The Schemes should develop elaborate revenue generating programmes such as local-specific NHIS education programmes backed by competent staff and the requisite logistics. Scheme expenditures could also be reduced through prudent administrative measures, robust claim processing procedures, and proper and complete documentation.

\section{CONCLUSION}

In conclusion, regular financial assessment of schemes using administrative cost, revenue, expenditure, and combine ratio will provide first hand information on its financial viability and general performance.

\section{ACKNOWLEDGEMENTS}

We thank the Scheme Managers of LDMHIS and SEDMHIS and their entire staff for their contribution to this study. We are also grateful to the Regional Directorate of Health Services and the Chief Executives of the study district for showing keen interest in our work. We thank Dr Mawuli K Gyakobo for his technical advice.

\section{REFERENCES}

1. Republic of Ghana. Hospital Fee Decree, 1969 (NLCD 360).

2. Republic of Ghana. Hospital Fees Act, 1970 (Act 387).

3. Republic of Ghana. Hospital Fee Regulations, 1985 (PNDC LI 1313).

4. Ghana/SAPRI (2001). Impact of SAP on availability of and access to health care. Draft April 2001. 
5. Gilson L. The lessons of user fee experience in Africa. Health Policy and Planning. 1997; 12(4): 273-285.

6. Aikins M. Tano Health Insurance Scheme, BrongAhafo Region. External Evaluation. 2004.

7. Asenso-Okyere W, Anum A, Osei-Akoto I and Adukonu A. Cost recovery in Ghana: Are there any changes in health care seeking behaviour? Health Policy and Planning 1998; 13: 181 - 188.

8. Waddington CJ and Enyimayew KA A price to pay, part 2: the impact of user-charges in the Volta Region of Ghana. Int $J$ of Health Planning and Management 2006; 4(1):17 - 47.

9. Nyonator F and Kutzin J. Health for some? The effects of user fees in the Volta Region of Ghana. Health Policy and Planning, 1999; 14(4): 329341.

10. Agyepong I and Adjei S. Public social policy development and implementation: a case study of the Ghana National Health Insurance scheme. Health Policy and Planning 2008; 23(2) 150-60

11. Republic of Ghana. National Health Insurance Act, 2003, (Act 650).

12. Republic of Ghana. National Health Insurance Regulation, 2004, (LI 1809).

13. Ministry of Health. National Health Insurance Policy Framework. Revised Version. Ministry of Health of Ghana. 2004 August.

14. Dror DM. Reinsurance of health insurance for the informal sector. Bull World Health Organization, 2001; 79(7); 672-8.

15. Wiesmann D and Jütting J. Determinants of Viable Health Insurance Schemes in Rural Sub-Saharan Africa: Quarterly J of Int Agriculture. 2001; 40 (4): 361-378.
16. Arhin-Tenkorang D. Health Insurance for the Informal Sector in Africa: Design Features, Risk Protection, and Resource Mobilization. $2001 \mathrm{CMH}$ Working Paper Series.

17. Ghana Health Service. Annual Report of Upper West Region, 2006 (Unpublished).

18. Saltman, RB, Busse, R and Figueras J. Social Health Insurance Systems in Western Europe. European Observatory on Health Systems and Policies Series, WHO, 2004: 3 - 29.

19. Mossialos E and S Thomson. Voluntary health insurance in the European Union, Copenhagen: WHO Regional Office for Europe on behalf of the European Observatory on Health Systems and Policies. 2004.

20. Arhinful DK. The Solidarity of Self-interest: Social and Cultural Feasibility of Rural Health Insurance in Ghana. African Studies Centre Publishers, Leiden. 2003. ISBN: 90.5448.055.6.

21. 21 Atim C. Contribution of Mutual Health Organizations to Financing, Delivery, and Access to Health Care: Partnerships for Health Reform, Technical Report No. 18. 1998. Abt Associates, Bethesda, MD.

22. Baltussen R, Bruce E, Rhodes G, Narh-Bana S.A, Agyepong I. Management of mutual health organizations in Ghana: Tropical Medicine and International Health 2006; 11(5):654-659.

23. Tabor S.R. Community-Based Health Insurance and Social Protection Policy. Social Protection Discussion Paper Series, 2005. World Bank Institutes. 